\title{
A paternal deletion of MKRN3, MAGEL2 and NDN does not result in Prader-Willi syndrome
}

\author{
Deniz Kanber ${ }^{1}$, Jacques Giltay ${ }^{2}$, Dagmar Wieczorek ${ }^{1}$, Corinna Zogel ${ }^{1}$, Ron Hochstenbach ${ }^{2}$, \\ Almuth Caliebe ${ }^{3}$, Alma Kuechler ${ }^{1}$, Bernhard Horsthemke ${ }^{1}$ and Karin Buiting ${ }^{*, 1}$
}

\author{
${ }^{1}$ Institut für Humangenetik, Universitätsklinikum Essen, Essen, Germany; ${ }^{2}$ Division of Medical Genetics, \\ University Medical Center Utrecht, Utrecht, The Netherlands; ${ }^{3}$ Institut für Humangenetik, Universitätsklinikum \\ Schleswig-Holstein, Campus Kiel, Kiel, Germany
}

The Prader-Willi syndrome (PWS) is caused by a 5-6 Mbp de novo deletion on the paternal chromosome 15, maternal uniparental disomy 15 or an imprinting defect. All three lesions lead to the lack of expression of imprinted genes that are active on the paternal chromosome only: MKRN3, MAGEL2, NDN, C15orf2, SNURF-SNRPN and more than $70 \mathrm{C} / \mathrm{D}$ box snoRNA genes (SNORDS). The contribution to PWS of any of these genes is unknown, because no single gene mutation has been described so far. We report on two patients with PWS who have an atypical deletion on the paternal chromosome that does not include MKRN3, MAGEL2 and NDN. In one of these patients, NDN has a normal DNA methylation pattern and is expressed. In another patient, the paternal alleles of these genes are deleted as the result of an unbalanced translocation $45, X, \operatorname{der}(X) t(X ; 15)(q 28 ; q 11.2)$. This patient is obese and mentally retarded, but does not have PWS. We conclude that a deficiency of MKRN3, MAGEL2 and NDN is not sufficient to cause PWS. European Journal of Human Genetics (2009) 17, 582-590; doi:10.1038/ejhg.2008.232; published online 10 December 2008

Keywords: Prader-Willi syndrome; imprinting; atypical deletions

\section{Introduction}

The Prader-Willi syndrome (PWS [MIM 176270]) is a neurogenetic disorder characterised by neonatal muscular hypotonia and failure to thrive, hyperphagia and obesity starting in early childhood, hypogonadism, short stature, small hands and feet, sleep apnoea, behavioural problems and mild-to-moderate mental retardation. $\mathrm{A} \sim 5-6 \mathrm{Mb} d e$ novo interstitial deletion of the paternal chromosome 15 [del(15)(q11-q13)pat], which includes the entire imprinted domain plus several non-imprinted genes, is found in the majority $(\sim 70 \%)$ of patients with PWS. The next most common genetic abnormality in PWS (25-30\%) is maternal uniparental disomy 15 [upd(15)mat], which most often arises from maternal meiotic nondisjunction

*Correspondence: Dr K Buiting, Institut für Humangenetik, Universitätsklinikum Essen, Hufelandstr 55, 45122 Essen, Germany.

Tel: + 49201 7234555; Fax: + 49201 7235900;

E-mail: karin.buiting@uni-due.de

Received 1 September 2008; revised 30 October 2008; accepted 31 October 2008; published online 10 December 2008 followed by mitotic loss of the paternal chromosome 15 . A few patients with PWS ( $\sim 1 \%)$ have apparently normal chromosomes 15 of biparental inheritance, but the paternal chromosome carries a maternal imprint (imprinting defect). All three lesions lead to the lack of expression of imprinted genes that are active on the paternal chromosome only: MKRN3, MAGEL2, NDN, C15orf2, SNURF$S N R P N$ and more than $70 \mathrm{C} / \mathrm{D}$ box snoRNA genes (see Figure 1). Recently, we reported the identification of two novel genes between NDN and C15orf2: PWRN1 and $P W R N 2 .{ }^{1}$ We now know that PWRN1 is a novel alternative start site of SNURF-SNRPN and that PWRN2 is a male germ cell-specific gene expressed from the haploid genome after meiosis (Wawrzik et al, unpublished).

The contribution of any of these genes to the PWS phenotype is unknown. Balanced translocations as well as atypical deletions may help to elucidate the contribution of each of these genes to PWS. So far, six cases with typical PWS or a PWS-like phenotype and a balanced translocation have been described..$^{2-7}$ All of them involve 

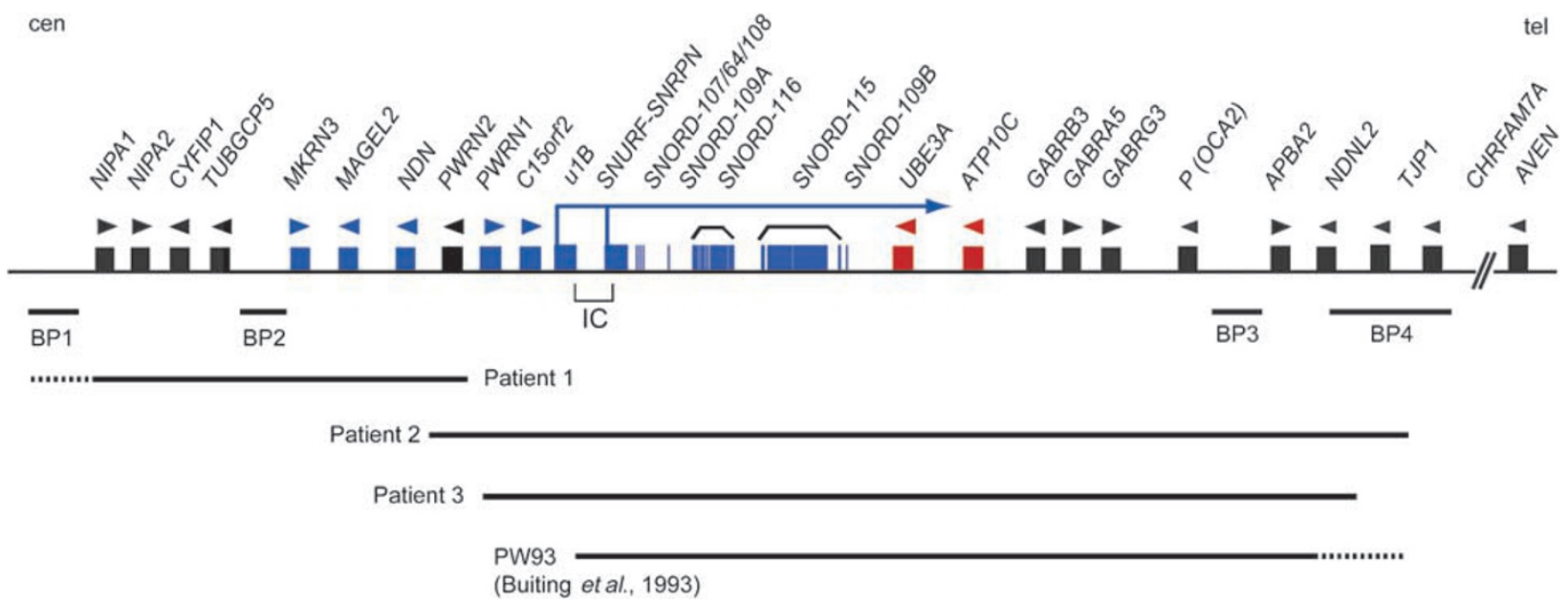

Figure 1 Physical map of 15q11-q13. Genes expressed from the maternal chromosome only are drawn as red boxes, genes expressed from the paternal chromosome only are drawn as blue boxes, snoRNA genes are indicated as blue vertical lines, genes expressed from both parental alleles are drawn as black boxes. The size of the deletions and localisation of the deletion breakpoints in patients 1, 2, 3 and PW93 ${ }^{19}$ are indicated below (black bars).

the SNURF-SNRPN locus. Two breakpoints are located in intron 2 and disrupt the SNURF-SNRPN coding region. The other breakpoints lie inside exon 17 (one case) or exon 20 within the $3^{\prime}$-untranslated region of the SNURF-SNRPN transcription unit. In all these cases, the translocation had no effect on the methylation of the SNURF-SNRPN locus or on the expression of the genes centromeric to SNURF$S N R P N$, but affected the expression of C/D box snoRNA genes (SNORDs), which are located within the SNURF$S N R P N$ transcription unit. Lack of expression of the SNORD116 genes (earlier HBII-85) has been shown in three of the six translocation patients. ${ }^{6-8}$ The SNORD115 gene cluster (earlier HBII-52) is unlikely to play a role in PWS, because individuals with a paternally derived deletion of these genes are normal. ${ }^{7,9}$

Recently, a patient with macrosomia and some features of PWS was reported to have a de novo deletion affecting the paternal copies of SNORD109A (earlier HBII-438A), the SNORD116 gene cluster and half of the SNORD115 gene cluster. ${ }^{10}$ Thus, the SNORD116 gene cluster may be a good candidate for some features of PWS. Here we report on three patients with an atypical deletion in 15q11-q13, who may help to further define the role of the $15 \mathrm{q} 11-\mathrm{q} 13$ genes in PWS.

\section{Methods \\ Patients}

Patient 1 The girl was born after an uneventful pregnancy. Birth weight was 3500 g. She drank very slowly but she did not need gavage feeding. Feeding problems remained until 18 months of age. Psychomotor development was delayed from birth onwards. At the age of 30 months she spoke her first words and she could walk without support. She was a quiet, somewhat shy, girl without any behavioural or sleeping problems. On account of her developmental delay, she was referred to a neurologist. He noticed an unstable gait, an asymmetric muscle tone of the legs, left foot in equinovarus position, increased reflexes of the legs with possibly a pathological reflex of the left foot sole. Diagnosis of a mild infantile hemiplegia of the left side was established. A CT scan of the brain showed no abnormalities.

At the age of 7 years, she was moderately retarded with the absence of hyperphagia, an apparently high pain threshold and no sleep disturbances. She had recently suffered from absences, which were confirmed by EEG and treated with valproic acid.

Her length was $140 \mathrm{~cm}(+2.5 \mathrm{SD})$, weight $41 \mathrm{~kg}(+1.5$ SD for length) and occipitofrontal circumference (OFC) was $54.5 \mathrm{~cm}(+2.0 \mathrm{SD})$. At physical examination, she had blond hair (like her mother), a full round face, biparietal narrowing, downslanting of the palpebral fissures, slight ptosis of the left eye, lumbar lordosis, valgus position of knees and feet, straight ulnar borders, no pigmentary or genital abnormalities (see Figure 2a).

At the age of $7 \frac{6}{12}$ years, she showed signs of puberty such as pubic hair and breast development. Endocrine investigations and the advanced bone age led to the diagnosis of an idiopathic precocious puberty. She was treated with triptorelin to inhibit pubertal development.

Both triptorelin and valproic acid treatments were stopped at the age of 12 years. Her length then was $160 \mathrm{~cm}(+1.0 \mathrm{SD})$ and her weight $75 \mathrm{~kg}(+2.5 \mathrm{SD})$. She eats a lot although she does not seem to have real hyperphagia. The bones of the left middle ear had to be reconstructed after recurrent otitis media. 

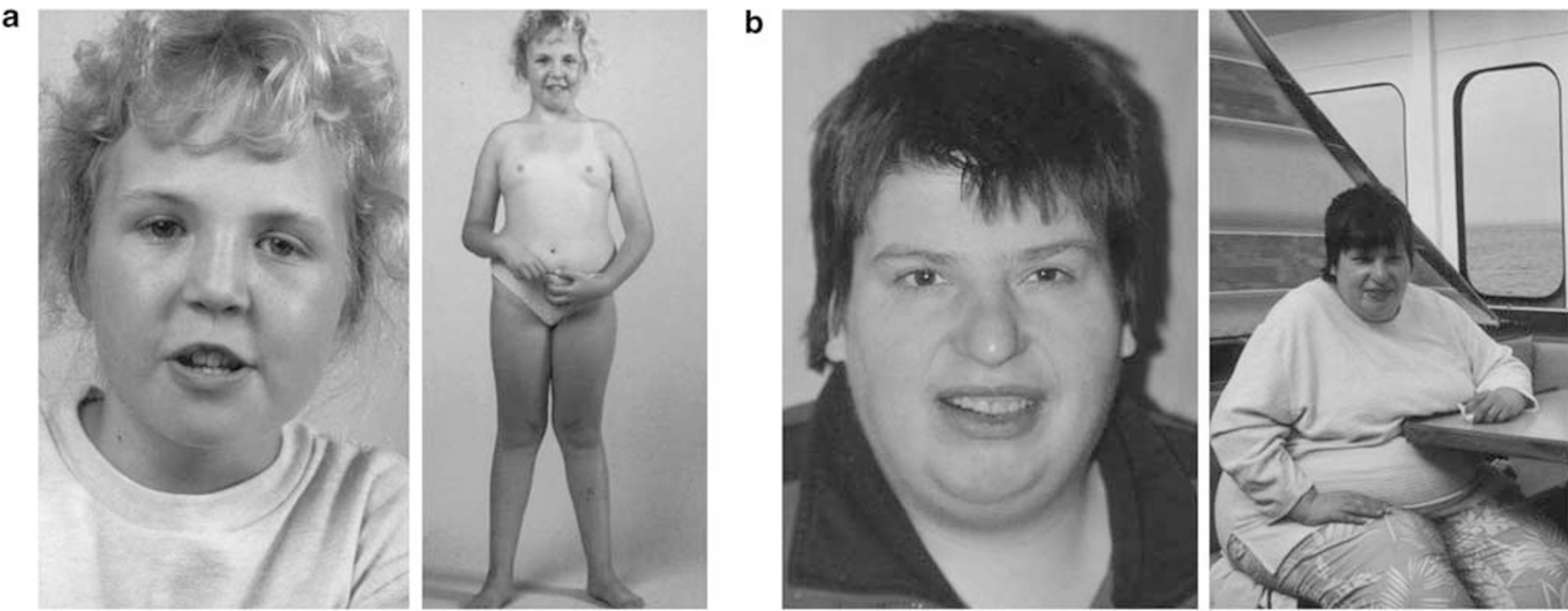

Figure 2 Photographs of the patients. (a) Patient 1 with the $t(X ; 15)(q 28 ; q 11.2)$. (b) Patient 3 with PWS and an atypical deletion in $15 q 11-q 13$.

Patient 2 Pregnancy was uneventful. Birth occurred at term from breech presentation with low birth weight (2750 g (-2.9 SD)). Shortly after birth, the patient suffered from inspiratory stridor, right-sided paresis of nervus facialis and left-sided paresis of nervus radialis. $\mathrm{He}$ presented with severe muscle hypotonia and decreased movements. Feeding difficulties required tube feeding for 2 months. Hypogenitalism (cryptorchidism and hypoplastic scrotum) was present. Psychomotor development was delayed with sitting without support at the age of 11 months and walking without support at the age of 20 months. In addition, he had premature synostosis of the coronal suture. At the age of 5 years, he presented with short stature (height: $102 \mathrm{~cm}(-2.0 \mathrm{SD})$ ), obesity (weight: $28.2 \mathrm{~kg}$ (BMI: 27)) and normocephaly (OFC: $51.5 \mathrm{~cm}$ (mean)). His hands and feet were small (hand length: $11 \mathrm{~cm}(-2.0 \mathrm{SD})$; foot length: $14 \mathrm{~cm}(-3.0 \mathrm{SD}))$. He was reexamined at the age of $14 \frac{6}{12}$ years. Short stature (height: $145 \mathrm{~cm}(-2.3 \mathrm{SD}))$ was still present and obesity severely increased (weight: $89.2 \mathrm{~kg}$ (BMI: 42)). At this time, he additionally presented with problems of articulation, varicosis and scoliosis. He was not able to tie his shoes. He developed diabetes mellitus at the age of 18 years. A therapy with naloxon to improve the hyperphagia was a failure.

Patient 3 Pregnancy was uneventful besides reduced intrauterine movements. Birth occurred at term with dystrophy (length: $49 \mathrm{~cm}(-1.5 \mathrm{SD})$; weight: $2700 \mathrm{~g}(-2.2$ $\mathrm{SD})$; OFC was not reported). Owing to severe feeding problems, gastric tube feeding was necessary for 10 weeks. Early development was delayed by severe muscle hypotonia. The parents reported that obesity started at the age of 5-6 years resulting in hyperphagia later in life. She has a primary amenorrhea, but denies gynaecological investigation.
We saw her for diagnostic evaluation at the age of 30 years: she presented with the characteristic PWS facial phenotype with almond-shaped eyes and a moderate mental retardation (see Figure $2 \mathrm{~b}$ ). She has normal stature $(155 \mathrm{~cm}(-1.9 \mathrm{SD}))$ and a normal OFC $(55.5 \mathrm{~cm}(+0.4 \mathrm{SD}))$. Her obesity is pronounced (127 kg (BMI: 53)). Her hands are small with a hand length of $16.2 \mathrm{~cm}(<-2.0 \mathrm{SD})$. Her feet are also small, but swollen due to lymphoedemas. She has no hypopigmentation, but a mild scoliosis, strabismus, viscous saliva, skin picking and high pain threshold. She lives in an institution for the mentally disabled and does not tolerate changes in daily life routine. Her severe hallucinations are successfully treated with zuclopenthixol, and her sleep apnoea also improved under this therapy.

The study was approved by the local ethics committee. Blood samples were obtained after informed consent.

\section{Cytogenetic and molecular cytogenetic analysis}

Short-term lymphocyte cultures from peripheral blood were prepared following standard procedures. Metaphases were analysed with GTG banding at the 550 band level (as determined by the ISCN 2005 standards). For studying the inactivation pattern of the $\mathrm{X}$ chromosome, we used BrdU incorporation in late replicating DNA, followed by acridine orange staining, producing an RBA-banding pattern. ${ }^{11}$ Fluorescence in situ hybridisation (FISH) was performed on metaphase chromosomes according to standard methods, ${ }^{12}$ except that after hybridisation, formamide was omitted from the washing buffer and slides were washed twice in $0.4 \times \mathrm{SSC} / 0.05 \%$ Tween-20 at $72^{\circ} \mathrm{C}$ for $5 \mathrm{~min}$, followed by washes in $2 \times \mathrm{SSC} / 0.05 \%$ Tween-20 and $4 \times$ SSC/0.05\% Tween-20 at room temperature for $5 \mathrm{~min}$ each. YAC probes from the $15 \mathrm{q} 11-\mathrm{q} 13$ region used for FISH were 71B11 and 307A12. We also used the LSI SNRPN (containing the SNRPN gene), LSI D15S10 (containing the 
UBE3A gene) and CEP 15 (locus D15Z1) from Vysis-Abbott (Downers Grove, IL, USA).

\section{DNA preparation}

DNAs were extracted and purified from blood using the FlexiGene DNA Kit (Qiagen, Hilden, Germany) following the manufacturer's instructions.

\section{Bisulphite treatment of genomic DNA}

Bisulphite treatment of genomic DNA was modified from established protocols. ${ }^{13}$ Genomic DNA $(2 \mu \mathrm{g}$ in $50 \mu \mathrm{l})$ was denatured by adding $5.5 \mu \mathrm{l}$ of freshly prepared $3 \mathrm{M} \mathrm{NaOH}$ and incubating the solution at $37^{\circ} \mathrm{C}$ for $15 \mathrm{~min}$. For complete denaturation, the samples were incubated at $95^{\circ} \mathrm{C}$ for $2 \mathrm{~min}$ and immediately cooled on ice. The bisulphite solution was prepared by dissolving $8.5 \mathrm{~g}$ of sodium bisulphite in $15 \mathrm{ml}$ of degassed water, adding $900 \mu \mathrm{l}$ of a $50 \mathrm{~mm}$ hydroquinone solution, and adjusting the $\mathrm{pH}$ to 5.1 with $1000 \mu \mathrm{l}$ of $10 \mathrm{M} \mathrm{NaOH}$. The bisulphite solution $(500 \mu \mathrm{l})$ was added to the denatured DNA, mixed and incubated at $50^{\circ} \mathrm{C}$ for $16 \mathrm{~h}$ in the dark. The DNA was recovered by using the Wizard DNA Clean-Up System (Promega) followed by elution in $50 \mu \mathrm{l}$ water. Subsequently, $5.5 \mu \mathrm{l}$ of $3 \mathrm{M} \mathrm{NaOH}$ was added and the samples were incubated for $15 \mathrm{~min}$ at $37^{\circ} \mathrm{C}$. The solution was then neutralised by adding $55 \mu \mathrm{l}$ of $6 \mathrm{M} \mathrm{NH}_{4} \mathrm{OAc}(\mathrm{pH}$ 7.0). The DNA was ethanol precipitated, washed in $70 \%$ ethanol, dried and resuspended in $30 \mu \mathrm{l}$ water.

\section{Methylation-specific PCR}

Genomic DNA was purified from whole blood and treated with sodium bisulphite according to standard methods. Methylation-specific PCR analysis was carried out for the SNURF-SNRPN locus as described by Zeschnigk et al. ${ }^{13}$

\section{Sequence-based quantitative methylation analysis}

The sequence-based quantitative methylation analysis (SeQMA) for the NDN locus was performed as described by Kanber et al. ${ }^{14}$ Specific primers used to amplify a $123 \mathrm{bp}$ region in the $5^{\prime}$ upstream region and inside the NDN gene are

NDN-MLPA-Ftag (5'-CTTGCTTCCTGGCACGAG-TGGAY GTAGAGGTTTTGTTTTTG-3') and NDN-MLPA-RM13 (5'-C AGGAAACAGCTATGAC-AAACCCCAAAACTACTATACACC TC- $\left.3^{\prime}\right)$. PCR conditions were as follows: $95^{\circ} \mathrm{C}$ for $10 \mathrm{~min}, 35$ cycles of $95^{\circ} \mathrm{C}$ for $20 \mathrm{~s}, 57^{\circ} \mathrm{C}$ for $20 \mathrm{~s}, 72^{\circ} \mathrm{C}$ for $30 \mathrm{~s}$, and finally $7 \mathrm{~min}$ at $72^{\circ} \mathrm{C}$.

\section{Methylation-specific multiplex ligation-dependent probe amplification}

For methylation and dosage analysis of the PWS/AS region, we used the methylation-specific multiplex ligationdependent probe amplification (MS-MLPA) SALSA kit ME028 (MRC Holland). We used a total of $400 \mathrm{ng}$ of genomic DNA for each sample tested. After $16 \mathrm{~h}$ of hybridisation at $60^{\circ} \mathrm{C}$, samples were split equally into two aliquots. The first aliquot underwent ligation only, whereas the second underwent ligation plus enzymatic digestion. The ligation, enzymatic digestion and PCR amplification were performed according to the manufacturer's instructions. PCR products $(1 \mu \mathrm{l})$ from each tube were mixed with $1 \mu \mathrm{l}$ of internal size standard (ROX-500 GeneScan; Applied Biosystems) and $20 \mu$ l of deionised formamide, and injected into an ABI-3100 genetic analyser (Applied Biosystems).

The GeneScan project was imported into a Genotyper file containing an appropriate table of categories and two macros for peak calling and data tabulation. Analysis of data was performed using a modified Excel spreadsheet that contains algorithms originally created for BRCA2 MLPA analysis and that we obtained from the Clinical Molecular Genetics Laboratory, Regional Clinical Genetics Service at St James's University Hospital in Leeds, UK (http://leedsdna.info/). Data sets for both the test samples and the average of the normal control samples were imported, corrected and internally adjusted in the raw data worksheet and dosage ratios for the probes (equivalent to dosage quotients) were calculated and listed in the analysis results section along with a probability value (for details see http://leedsdna.info/downloads.htm).

\section{RNA preparation}

Total RNA from a lymphoblastoid cell line was prepared with QIAamp RNA Blood Mini Kit following the manufacturer's instructions. For reverse transcriptase PCR (RT-PCR) experiments, RNA was treated with DNase I to remove residual traces of genomic DNA.

\section{Reverse transcriptase PCR}

RT-PCRs were performed with the GeneAmp RNA PCR Kit (Perkin Elmer). Total RNA from blood or lymphoblastoid cell lines $(1 \mu \mathrm{g})$ was reverse transcribed using random hexamers. The cDNA products were amplified by 35 cycles of PCR. The primers used were as follows: RN134 and RN175 for SNURF-SNRPN exons 1 and $2 .^{2}$ For NDN, we used primers RN700 (5'-AGCCCCAAAAGAACTCGTATT- $3^{\prime}$ ) and RN709 (5'-CAGAAGGCGCACGAGCTC-3'). The integrity of the RNA samples was shown by amplification of a 496-bp transcript fragment from the $\beta$-actin locus. ${ }^{15}$

\section{Microsatellite analysis}

Markers on distal Xq (DXS1073 and DXS1108, the latter being the most distal) were analysed as follows. The PCR for these marker analyses contained 50 ng DNA, $0.25 \mu \mathrm{l}$ marker, $0.08 \mu \mathrm{l}$ Taq gold, $1 \mu \mathrm{l}$ buffer II, $25 \mathrm{mM} \mathrm{MgCl}, 2 \mathrm{mM}$ dNTPs and $5.67 \mu \mathrm{l}$ Aqua Dest. The amplification was carried out by $10 \mathrm{~min}$ denaturation at $95^{\circ} \mathrm{C}$ followed by 33 cycles of denaturation $\left(30 \mathrm{~s}\right.$ at $\left.95^{\circ} \mathrm{C}\right)$, annealing $\left(30 \mathrm{~s}\right.$ at $\left.72^{\circ} \mathrm{C}\right)$ and elongation $\left(30 \mathrm{~s}\right.$ at $\left.72^{\circ} \mathrm{C}\right)$. The PCR products were checked on agarose gels, run on an ABI3100 and analysed using GeneScan software. 


\section{SNP microarray analysis}

From individual samples, $250 \mathrm{ng}$ DNA was analysed on the GeneChip Human Mapping 250K Sty array (Affymetrix, Santa Clara, CA, USA) according to the manufacturer's protocol (see the GeneChip ${ }^{\circledR}$ Mapping 500K Assay Manual for full protocol). Imaging of the microarrays was performed using the GCS3000-G7 scanner from Affymetrix. Genotype calls and probe-intensity data were extracted with the GTYPE4.1 software from Affymetrix setting the call threshold for homozygous and heterozygous calls to 0.26 (250K arrays). Copy number analysis was performed using the software CNAG v2.0 (Copy Number Analyzer for GeneChip, ${ }^{16}$ http://www.genome.umin.jp). The design of the Human Gene 250K Array was based on the March 2006 human genome sequence assembly (UCSC Hg18). Conspicuous regions were compared with known CNVs, as provided by the Database of Genomic Variants.

\section{Results}

Cytogenetic and molecular investigations in a patient with an unbalanced translocation 45,X,der(X)t(X;15)(q28;q11. 2) (patient 1)

Conventional cytogenetic analysis in patient 1 revealed a de novo 45, $\mathrm{X}, \operatorname{der}(\mathrm{X}) \mathrm{t}(\mathrm{X} ; 15)(\mathrm{q} 28 ; \mathrm{q} 11.2)$ karyotype (Figure 3$)$. The patient is monosomic for the chromosomal regions 15pter-15q11.2 and Xq28-qter. FISH with locus-specific probes derived from the Prader-Willi syndrome critical region (YAC clone 71B11, which maps close but telomeric to NDN; YAC clone 307A12, which covers PWRN1 and a probe specific for $S N R P N)$ hybridised to the $\operatorname{der}(\mathrm{X})$ chromosome, indicating that these target regions were present in two copies (data not shown). Microsatellite analysis of the telomeric part of the $\mathrm{X}$ chromosome revealed that the translocation breakpoint maps between the markers DXS1073 and DXS1108. The patient was found to have only the maternally derived allele of DXS1108, indicating that the $\operatorname{der}(\mathrm{X})$ chromosome was of paternal origin (data not shown).

RBA staining showed that the $\operatorname{der}(\mathrm{X})$ chromosome was late replicating in all the cells analysed, whereas the chromosome 15-derived part of this $\operatorname{der}(\mathrm{X})$ chromosome appeared to be early replicating (not shown). To find out a possible spreading of $\mathrm{X}$ inactivation into the chromosome 15 part of the $\operatorname{der}(\mathrm{X})$ chromosome, which may silence genes in 15q11-q13, we studied methylation and expression of the SNURF-SNRPN locus. Methylation analysis by methylation-specific PCR for the exon 1/promoter region of SNURF-SNRPN ${ }^{13}$ showed a normal biparental methylation pattern at this locus (data not shown). To investigate the expression of SNURF-SNRPN, we performed RT-PCR with primers RN134 and RN175, which anneal to exons 1 and 2. As a template we used lymphoblastoid cell line RNA and peripheral blood RNA from the patient as well as blood RNA from a normal control. As a control, an RT-PCR

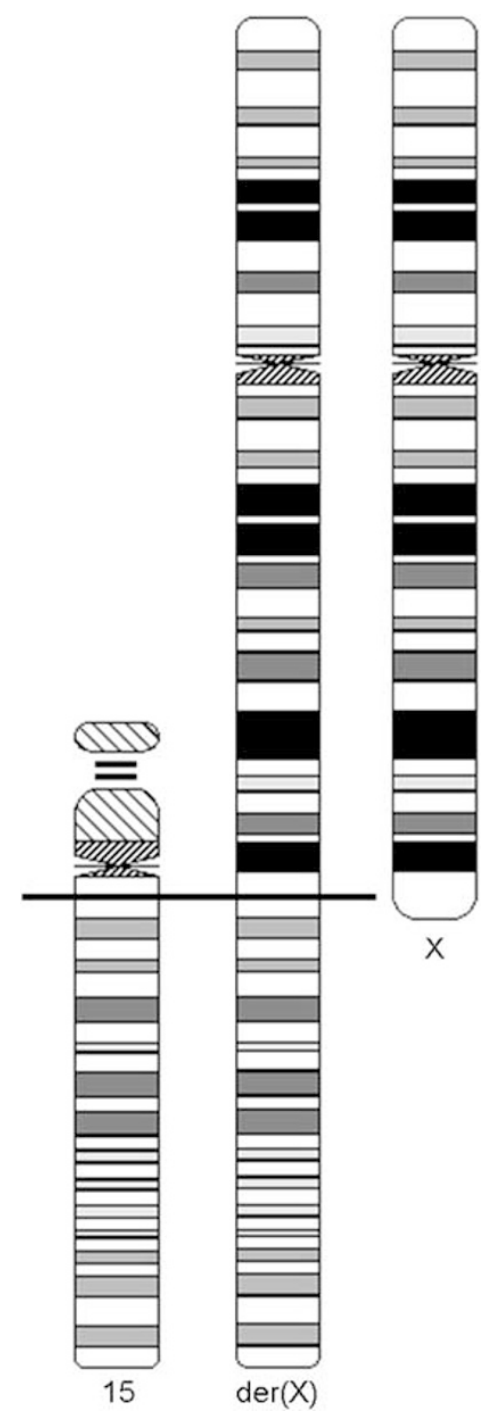

Figure 3 Schematic result of the cytogenetic analysis of the translocation in patient 1. Partial ideogram according to ISCN 2005; from left to right: normal chromosome $15, \operatorname{der}(X)$ and chromosome $X$. The translocation breakpoints in $15 q 11$ and $\mathrm{Xq} 28$ are indicated by a horizontal line.

product for the $\beta$-actin locus was amplified in all three RNA samples in the same reaction. As shown in Figure 4, RT-PCR products of the expected size were obtained. Comparison of the intensity of the RT-PCR products for SNURF-SNRPN and the RT-PCR products for $\beta$-actin revealed no evidence for a reduced SNURF-SNRPN expression in the patient.

To localise the translocation breakpoint in $15 \mathrm{q} 11$, we performed dosage analysis throughout 15q11-q13 by MLPA on DNA from the translocation patient. By this, we found that the patient is deleted for the non-imprinted genes CYFIP1 and TUBGCP5, and the paternally expressed genes MKRN3, MAGEL2 and NDN, indicating that the translocation breakpoint lies inside the critical PWS region 


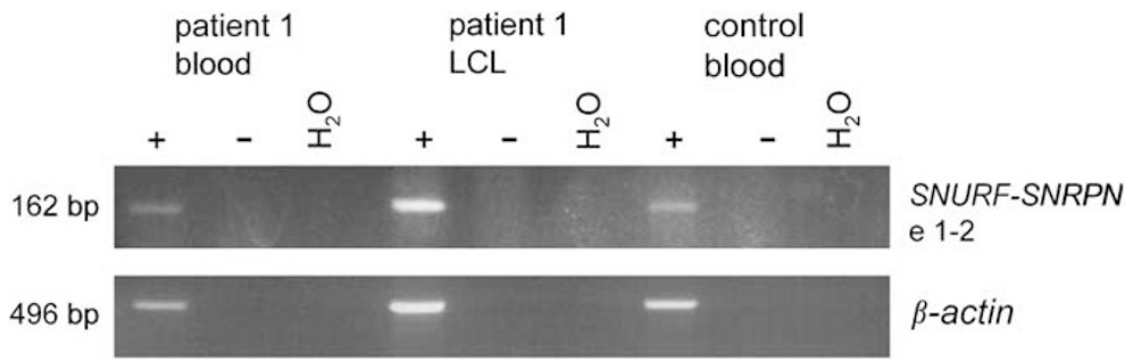

Figure 4 Expression analysis in blood and lymphoblastoid cell line (LCL) RNA from patient 1 for exons $1-2$ of SNURF-SNRPN. Compared with the normal control and the $\beta$-actin RT-PCR product no reduced SNURF-SNRPN expression level could be observed.

between NDN and SNURF-SNRPN. To further map the translocation breakpoints in $15 \mathrm{q} 11$ and $\mathrm{Xq} 28$ more precisely, we used the GeneChip Human Mapping 250K Sty array (Affymetrix). By this, the translocation breakpoint on chromosome 15 was found to be between rs1846338 (chr.15: 22021827 bp, UCSC, hg18), which was deleted, and rs11161080 (chr.15: $22199087 \mathrm{bp}$, UCSC, hg18), which was intact. Thus, this breakpoint maps between PWRN2 and PWRN1, in a region for which a complex duplication pattern has been described recently (Supplementary Figure 1). ${ }^{1}$ For the telomeric region in $\mathrm{Xq}$, the last but one single-nucleotide polymorphism (SNP) rs479901 (chr.X: 154497481 bp, UCSC, hg18) was not deleted and the most telomeric SNP rs672932 (chr.X: $154569169 \mathrm{bp}$, UCSC, hg18) was not informative. However, from microsatellite analysis, the STS marker DXS1108 (chr.X: 154515043-154515206 bp, UCSC, hg18) was found to be deleted. Thus, the deletion breakpoint on $\mathrm{Xq}$ maps between rs479901 and DXS1108 and includes the four genes of the pseudoautosomal region 2: SPRY3, VAMP7 (SYBL1), IL9R and CXYorf1 (WASH6P).

\section{Atypical deletions in two patients with PWS (patients 2 and 3$)$}

In the majority of patients with PWS with a 15q11-q13 deletion, the breakpoints are in the common breakpoint cluster regions BP1 or BP2 and BP3. By deletion screening with MLPA, we identified atypical deletions in two patients with all typical features of PWS (see Table 1). In both cases, the deletion does not include MKRN3, MAGEL2 and NDN, which lie in the more centromeric part of the critical PWS region. Both patients are also deleted for the $A P B A 2$ gene in $15 q 13$, indicating that the telomeric breakpoint maps distal to BP3.

SNP array analysis (GeneChip Human Mapping 250K Sty array) revealed that the centromeric breakpoint in patient 2 maps between SNP rs1524842 and rs2140005 (chr.15: $21505342-21560381 \mathrm{bp}$, UCSC, hg18), approximately 22$77 \mathrm{~kb}$ distal to NDN. The centromeric breakpoint of patient 3 lies inside the PWRN1 exonic region between rs7496441 and rs12717748 (chr.15: 22 278 324-22 339434 bp, UCSC, hg18), approximately $800-850 \mathrm{~kb}$ distal to $N D N$. The telomeric breakpoint in both patients maps inside the BP4 region. The telomeric breakpoint in patient 2 could be mapped distal to the TJP1 gene between rs6492918 and rs2046362 (chr.15: $28083156-28723577$ bp, UCSC, hg18), whereas the telomeric breakpoint in patient 3 maps between NDNL2 and TJP1 (rs509639 and rs817957, chr.15: $27338756-$ 27410092 bp, UCSC, hg18) (Supplementary Figure 1).

In patients with Prader-Willi syndrome and an imprinting centre (IC) deletion, the paternal alleles of imprinted genes centromeric to the deletion are methylated and silenced. In patients 2 and 3, the deletion includes the IC. As shown by MS-MLPA, patient 3 has the expected PWS methylation pattern at NDN. In contrast, patient 2 has a normal NDN methylation pattern. The MLPA result could be confirmed by SeQMA (Figure 5). Furthermore, the investigation of NDN by RT-PCR analysis of RNA from a lymphoblastoid cell line revealed that this gene is expressed in patient 2 , a result that is compatible with the methylation results (Figure 6).

\section{Discussion}

All patients with typical PWS described so far have a de novo deletion of $15 \mathrm{q} 11-\mathrm{q} 13$ on their paternal chromosome, maternal uniparental disomy 15 or an imprinting defect. Atypical deletions in patients with PWS are rare. Here we report on two patients with an atypical deletion that includes C15orf2 and the SNURF-SNRPN locus, but not MKRN3, MAGEL2 and NDN. Both patients have all features of PWS (see Table 1 and Figure 2b). The same is true for a patient first described by Robinson et al ${ }^{18}$ (PW93). In this patient, we were earlier able to detect the centromeric deletion breakpoint by Southern blot analysis and mapped it $20-25 \mathrm{~kb}$ upstream of the alternative SNURF-SNRPN start site $u 1 B$ (Figure 1). ${ }^{19}$ As all three patients are deleted for the chromosome 15 IC, it is likely that the IC deletion has led to an abnormal methylation and loss of gene expression of the non-deleted paternally active genes. Indeed, we observed an abnormal methylation pattern at the NDN locus in patient 3 . Unexpectedly, however, patient 2 has a 
Table 1 Clinical findings

\begin{tabular}{|c|c|c|c|}
\hline Clinical findings & $\begin{array}{l}\text { Patient } 1 \\
t(X ; 15)\end{array}$ & $\begin{array}{c}\text { Patient } \\
2\end{array}$ & $\begin{array}{c}\text { Patient } \\
3\end{array}$ \\
\hline \multicolumn{4}{|l|}{ Major criteria* } \\
\hline Hypotonia & - & + & + \\
\hline Feeding problems & - & + & + \\
\hline Obesity & + & + & + \\
\hline Hyperphagia & - & + & + \\
\hline Hypogonadism & - & + & + \\
\hline Developmental delay & + & + & + \\
\hline Characteristic facial features & - & + & + \\
\hline \multicolumn{4}{|l|}{ Minor criteria* } \\
\hline $\begin{array}{l}\text { Characteristic behavioural } \\
\text { problems }\end{array}$ & - & + & + \\
\hline Sleep disturbances/sleep & - & ND & + \\
\hline \multicolumn{4}{|l|}{ apnoea } \\
\hline Short stature & - & + & $(+)$ \\
\hline Hypopigmentation & - & - & - \\
\hline Small hands/small feet & $-1-$ & $(+) /+$ & $+1-$ \\
\hline Thick viscous saliva & - & + & + \\
\hline 'Skin picking' & - & - & + \\
\hline Decreased foetal movement & - & + & + \\
\hline Articulation defect & - & + & + \\
\hline Oesotropia/myopia & $-/ N D$ & $-1-$ & $(+) /-$ \\
\hline \multicolumn{4}{|l|}{ Supportive findings } \\
\hline High pain threshold & + & ND & + \\
\hline \multicolumn{4}{|l|}{ PWS atypical findings } \\
\hline Normal birth weight & + & - & - \\
\hline Hemiplegia & + & - & - \\
\hline Absence attack & + & $(+)$ & - \\
\hline Precocious puberty & + & - & - \\
\hline Accelerated bone age & + & - & - \\
\hline Overgrowth & + & - & - \\
\hline
\end{tabular}

ND, not detected (not reported); PWS, Prader-Willi syndrome; +, present; -, absent.

${ }^{*}$ Consensus diagnostic criteria for PWS. ${ }^{17}$

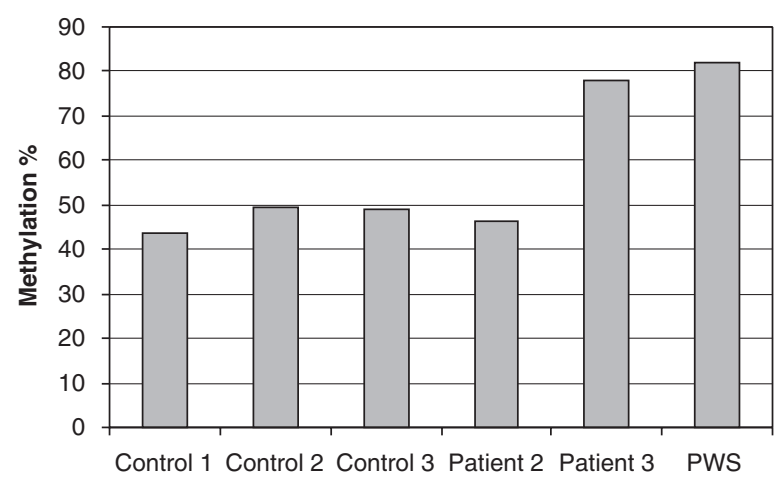

Figure 5 Methylation analysis of the NDN CpG island by SeQMA. Patient 3 shows a methylation pattern typical for PWS, whereas patient 2 shows a normal methylation pattern.

normal methylation pattern at this locus and NDN is expressed, at least in blood cells. We do not know why DNA methylation of this locus is different in the two

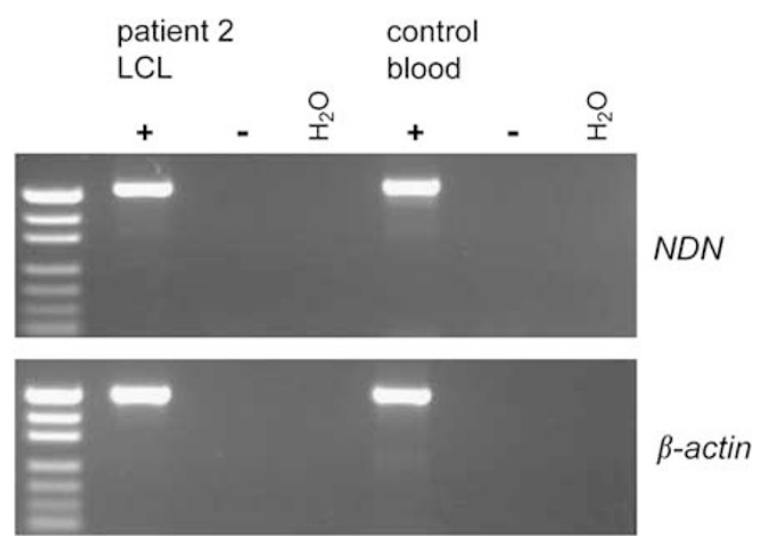

Figure 6 Expression analysis of NDN in RNA of lymphoblastoid cell line $(\mathrm{LCL}) \mathrm{RNA}$ from patient 2.

patients, but it is possible that this is due to a position effect of the deletion breakpoints. In patient 2 , the deletion breakpoint maps very close to the NDN promoter $(22-77 \mathrm{~kb})$, whereas the breakpoint in patient 3 is approximately $800 \mathrm{~kb}$ away from the gene. Anyhow, the findings in patient 2 are difficult to reconcile with a major role of NDN in PWS.

In contrast to patients 2, 3 and PW93, patient 1 is deleted for MKRN3, MAGEL2 and NDN, but has no clinical symptoms of PWS except for obesity, developmental delay and a high pain threshold (Table 1 and Figure 2a). It is possible that the clinical features unrelated to PWS in this patient are caused by haploinsufficiency of the pseudoautosomal region 2 in Xq28. However, a phenotype associated with a deletion of this region has not yet been described in the literature. Furthermore, we cannot exclude silencing of $15 \mathrm{q}$ genes by the spreading of $\mathrm{X}$ inactivation into the chromosome 15 part of the $\operatorname{der}(\mathrm{X})$ chromosome, although we have not found any evidence for this. Furthermore, we cannot exclude mosaic inactivation in other tissues either. In summary, we conclude that a paternal deficiency of MKRN3, MAGEL2 and NDN is not sufficient to cause PWS.

On the basis of six patients with balanced translocations affecting the SNURF-SNRPN locus, who were described to have typical PWS or a PWS-like phenotype, the snoRNA genes located in the large SNURF-SNRPN transcripts may be responsible for at least several features of PWS. ${ }^{2-7}$ These are the single-copy snoRNA genes SNORD64, SNORD107, SNORD108, SNORD109A and -109B (earlier HBII-13, HBII436, HBII-437, HBII-438A and -B) and the two snoRNA gene clusters SNORD115 and SNORD116. In two unrelated families, a small deletion spanning UBE3A and the SNORD115 gene cluster has been identified. Although maternal transmission of the deletions leads to Angelman syndrome, paternal transmission is not associated with an obvious clinical phenotype. ${ }^{20-22}$ This excludes the 
SNORD115 snoRNAs from a role in PWS. The SNORD116 gene cluster maps distal to six balanced translocation breakpoints in patients with some features of PWS. As SNORD116 is not expressed in these patients, ${ }^{6,7}$ this snoRNA may play a role in PWS.

In a recent study, Sahoo et $\mathrm{al}^{10}$ described a patient with some features of PWS, such as neonatal hypotonia, feeding problems, obesity and hypogenitalism. Atypical features included high birth weight, macrosomia, macrocephaly, absence of mental retardation and an atypical face. The patient is deleted for the paternal copies of SNORD109A, the SNORD116 gene cluster and half of the SNORD115 gene cluster. In contrast to this patient, mice deficient for this gene cluster are not macrosomic, but runty. ${ }^{23,24}$ Unless additional patients with an SNORD116 deletion are found, it is difficult to define the role of SNORD116 deficiency in PWS.

The findings in mouse models are difficult to reconcile with the findings in human patients. Although mice deficient for MAGEL2 and NDN show some features reminiscent of PWS, ${ }^{25-29}$ patient 1 demonstrates that a paternal deficiency of these genes is not sufficient to cause PWS, although we cannot exclude that it contributes to obesity, mental retardation and high pain threshold in this patient. The deletions described here point to a critical PWS region including C15orf2, SNURF-SNRPN and the SNORD genes. C15orf2 is not conserved in mice, ${ }^{30}$ which precludes the generation of a mouse model for this gene. It is tempting to speculate that the lack of a good mouse model for PWS is partly related to the differences in the gene content of 15q11-q13 and the orthologous region in the mouse. Mice deficient for SNURF and SNRPN do not have any abnormal phenotype, ${ }^{31}$ but this does not exclude the role of this gene in PWS, because patients with a translocation breakpoint in intron 2 have many features of PWS. ${ }^{2,3}$ Of course, these features may be due to a deficiency of the snoRNAs encoded within the SNURF-SNRPN transcription unit. However, as noted above, the patients with the SNORD116 deletion ${ }^{10}$ as well as mice deficient for this gene cluster $^{23,24}$ do not have a typical PWS phenotype. Furthermore, it cannot be excluded that the loss of the untranslated SNURF-SNRPN exons included in the human deletion and the mouse deletion contributes to the phenotype. In mice, it will be necessary to demonstrate that the reintroduction of the SNORD116 genes without the SNURF-SNRPN exons rescues the phenotype.

Despite other claims, ${ }^{10,32}$ we suggest that PWS is not caused by a single-locus defect, but by a deficiency of several genes in the region that includes C15orf2, SNURF$S N R P N$ and the SNORD genes. Furthermore, it cannot be excluded that a deficiency of MKRN3, MAGEL2 and/or $N D N$ is necessary, although not sufficient to generate the full PWS phenotype. For understanding the role of the 15q11-q13 genes in PWS, more patients need to be examined.

\section{Acknowledgements}

We thank the patients and the families for their cooperation, Ludger Klein-Hitpaß for SNP array analysis, Norbert Hödebeck-Stuntebeck for assistance in the clinical evaluation of patient 3 and Christina Lich for expert technical assistance. This study was supported by the Deutsche Forschungsgemeinschaft (BU907/1-4) and the EU (LSHM-CT-2005512136).

\section{References}

1 Buiting K, Nazlican H, Galetzka D, Wawrzik M, Gross S, Horsthemke B: C15orf2 and a novel noncoding transcript from the Prader-Willi/Angelman syndrome region show monoallelic expression in fetal brain. Genomics 2007; 89: 588-595.

2 Sun Y, Nicholls RD, Butler MG, Saitoh S, Hainline BE, Palmer CG: Breakage in the SNRPN locus in a balanced $46, \mathrm{XY}, \mathrm{t}(15 ; 19)$ Prader-Willi syndrome patient. Hum Mol Genet 1996; 5: 517-524.

3 Kuslich CD, Kobori JA, Mohapatra G, Gregorio-King C, Donlon TA: Prader-Willi syndrome is caused by disruption of the SNRPN gene. Am J Hum Genet 1999; 64: 70-76.

4 Schulze A, Hansen C, Skakkebaek NE, Brondum-Nielsen K, Ledbeter DH, Tommerup N: Exclusion of SNRPN as a major determinant of Prader-Willi syndrome by a translocation breakpoint. Nat Genet 1996; 12: 452-454.

5 Conroy JM, Grebe TA, Becker LA et al: Balanced translocation $46, \mathrm{XY}, \mathrm{t}(2 ; 15)(\mathrm{q} 37.2 ; \mathrm{q} 11.2)$ associated with atypical Prader-Willi syndrome. Am J Hum Genet 1997; 61: 388-394.

6 Wirth J, Back E, Huttenhofer A et al: A translocation breakpoint cluster disrupts the newly defined $3^{\prime}$ end of the SNURF-SNRPN transcription unit on chromosome 15. Hum Mol Genet 2001; 10: 201-210.

7 Schule B, Albalwi M, Northrop E et al: Molecular breakpoint cloning and gene expression studies of a novel translocation $\mathrm{t}(4 ; 15)(\mathrm{q} 27 ; \mathrm{q} 11.2)$ associated with Prader-Willi syndrome. BMC Med Genet 2005; 6: 18.

8 Gallagher RC, Pils B, Albalwi M, Francke U: Evidence for the role of PWCR1/HBII-85 C/D box small nucleolar RNAs in Prader-Willi syndrome. Am J Hum Genet 2002; 71: 669-678.

9 Ding F, Prints Y, Dhar MS et al: Lack of Pwcr1/MBII-85 snoRNA is critical for neonatal lethality in Prader-Willi syndrome mouse models. Mamm Genome 2005; 16: 424-431.

10 Sahoo T, del Gaudio D, German JR et al: Prader-Willi phenotype caused by paternal deficiency for the HBII-85 C/D box small nucleolar RNA cluster. Nat Genet 2008; 40: 719-721.

11 Koehler A: Chromosome staining; in Wegner ED (ed):: Diagnostic Cytogenetics. Berlin: Springer Verlag, 1999, pp 52-74.

12 Liehr T, Claussen U: FISH on chromosome preparations of peripheral blood; in Rautenstrauß BW, Liehr T (eds):: FISH Technology. Berlin: Springer Verlag, 2002, pp 73-81.

13 Zeschnigk M, Schmitz B, Dittrich B, Buiting K, Horsthemke B, Doerfler W: Imprinted segments in the human genome: different DNA methylation patterns in the Prader-Willi/Angelman syndrome region as determined by the genomic sequencing method. Hum Mol Genet 1997; 6: 387-395.

14 Kanber D, Buiting K, Zeschnigk M, Ludwig M, Horsthemke B: Low frequency of imprinting defects in ICSI children born small for gestational age. Eur J Hum Genet, doi:10.1038/ejhg.2008.177.

15 Buiting K, Barnicoat A, Lich C, Pembrey M, Malcolm S, Horsthemke B: Disruption of the bipartite imprinting center in a family with Angelman syndrome. Am J Hum Genet 2001; 68: $1290-1294$.

16 Nannya Y, Sanada M, Nakazaki K et al: A robust algorithm for copy number detection using high-density oligonucleotide single nucleotide polymorphism genotyping arrays. Cancer Res 2005; 65: 6071-6079.

17 Holm VA, Cassidy SB, Butler MG et al: Prader-Willi syndrome: consensus diagnostic criteria. Pediatrics 1993; 91: 398-402. 
18 Robinson WP, Bottani A, Xie YG et al: Molecular, cytogenetic, and clinical investigations of Prader-Willi syndrome patients. Am J Hum Genet 1991; 49: 1219-1234.

19 Buiting K, Dittrich B, Gross S et al: Molecular definition of the Prader-Willi syndrome chromosome region and orientation of the SNRPN gene. Hum Mol Genet 1993; 2: 1991-1994.

20 Hamabe J, Kuroki Y, Imaizumi K et al: DNA deletion and its parental origin in Angelman syndrome patients. Am J Med Genet 1991; 41: 64-68.

21 Burger J, Horn D, Tonnies H, Neitzel H, Reis A: Familial interstitial $570 \mathrm{kbp}$ deletion of the UBE3A gene region causing Angelman syndrome but not Prader-Willi syndrome. Am J Med Genet 2002; 111: $233-237$.

22 Runte M, Varon R, Horn D, Horsthemke B, Buiting K: Exclusion of the C/D box snoRNA gene cluster HBII-52 from a major role in Prader-Willi syndrome. Hum Genet 2005; 116: 228-230.

23 Skryabin BV, Gubar LV, Seeger B et al: Deletion of the MBII-85 snoRNA gene cluster in mice results in postnatal growth retardation. PLoS Genet 2007; 3: e235.

24 Ding F, Li HH, Zhang S et al: SnoRNA Snord116 (Pwcr1/MBII-85) deletion causes growth deficiency and hyperphagia in mice. PLoS ONE 2008; 3: e1709.

25 Bischof JM, Stewart CL, Wevrick R: Inactivation of the mouse Magel2 gene results in growth abnormalities similar to Prader-Willi syndrome. Hum Mol Genet 2007; 16: 2713-2719.
26 Kozlov SV, Bogenpohl JW, Howell MP et al: The imprinted gene Magel2 regulates normal circadian output. Nat Genet 2007; 39: $1266-1272$.

27 Gerard M, Hernandez L, Wevrick R, Stewart CL: Disruption of the mouse necdin gene results in early post-natal lethality. Nat Genet 1999; 23: 199-202

28 Muscatelli F, Abrous DN, Massacrier A et al: Disruption of the mouse Necdin gene results in hypothalamic and behavioral alterations reminiscent of the human Prader-Willi syndrome. Hum Mol Genet 2000; 9: 3101-3110.

29 Andrieu D, Meziane H, Marly F, Angelats C, Fernandez PA, Muscatelli F: Sensory defects in Necdin deficient mice result from a loss of sensory neurons correlated within an increase of developmental programmed cell death. BMC Dev Biol 2006; 6: 56

30 Farber C, Gross S, Neesen J, Buiting K, Horsthemke B: Identification of a testis-specific gene (C15orf2) in the Prader-Willi syndrome region on chromosome 15. Genomics 2000; 65: $174-183$.

31 Tsai TF, Jiang YH, Bressler J, Armstrong D, Beaudet AL: Paternal deletion from Snrpn to Ube3a in the mouse causes hypotonia, growth retardation and partial lethality and provides evidence for a gene contributing to Prader-Willi syndrome. Hum Mol Genet 1999; 8: 1357-1364

32 Kishore S, Stamm S: The snoRNA HBII-52 regulates alternative splicing of the serotonin receptor 2C. Science 2006; 311: 230-232.

Supplementary Information accompanies the paper on European Journal of Human Genetics website (http://www.nature.com/ejhg) 